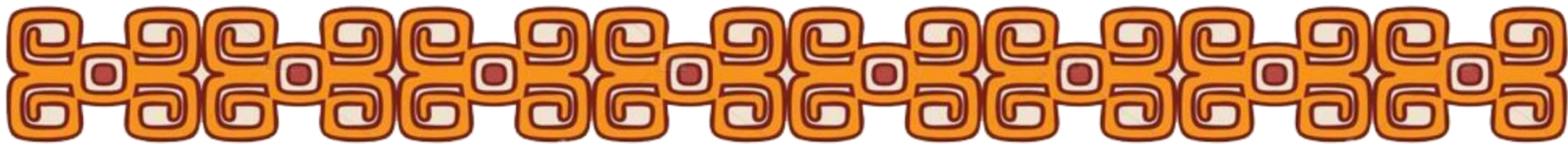

\title{
EM BUSCA DAS ORIGENS DOS SERES HUMANOS NO CONTINENTE AMERICANO: UM ESTUDO DE CASO
}

\author{
Gabriel Frechiani de Oliveira \\ Pedro Paulo Abreu Funari \\ Michel Justamand \\ Jaqueline Feitosa Batista
}

RESUMO

O presente trabalho tem por finalidade investigar as origens dos seres humanos no continente americano, levando em consideração as três principais perspectivas de povoamento: a) discurso religioso cristão fundamentalista; b) discurso acerca dos povos da antiguidade; c) o discurso científico fundamentado em dados e vestígios arqueológicos. A principal justificativa surge da importância de ressaltarmos a busca pelas vias de povoamento dos primeiros grupos humanos no continente americano, no intuito de demonstrar as várias possibilidades e, não focalizando apenas o povoamento via estreito de Bering, no norte do continente americano.

\section{PALAVRAS-CHAVES}

Povoamento do continente americano; Arqueologia; Análise do discurso.

\section{INTRODUÇÃO}

O povoamento do continente americano pelos seres humanos constitui um assunto que gera muitas controvérsias no meio acadêmico, os pesquisadores não dispõem de informações conclusivas acerca de qual seria o primeiro ponto que os seres humanos adentraram no continente oriundos de outras partes do mundo, devido à ausência de grandes primatas fósseis e homens pré-sapiens.

Ao realizarmos uma pequena revisão na literatura sobre as origens dos seres humanos no continente americano, desde do período do "descobrimento" até os dias atuais, podemos dividi-las em três categorias: a primeira de origens bíblicas; a segunda, de origens dos povos da antiguidade e; a terceira, baseada em dados científicos, a partir de descobertas arqueológicas, em particular, a qual será enfatizada ao longo desse capítulo.

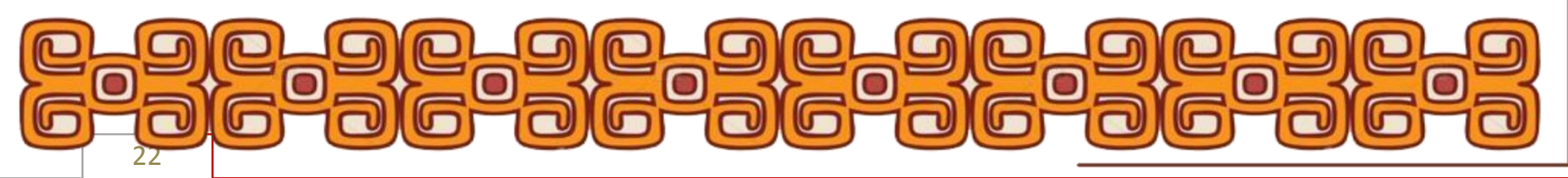




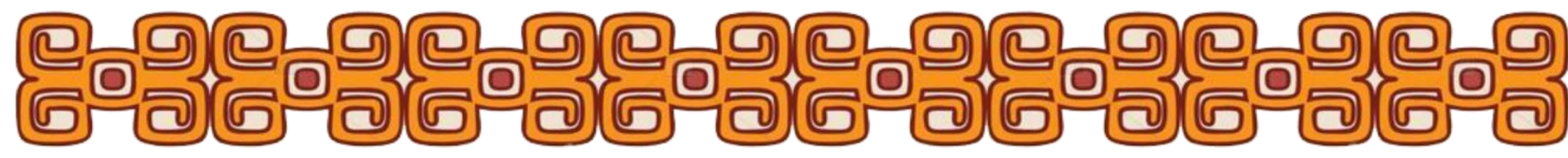

\section{DESENVOLVIMENTO}

\subsection{O DISCURSO DE ORIGEM BÍBLICA}

O discurso de origem bíblica do povoamento do continente americano estava baseado na possibilidade de os netos de Noé terem seus descendentes espalhados pelo mundo. Desde que iniciou o processo de colonização do continente americano, no final do século XV e XVI, no continente americano, houve a construção de uma identidade para aqueles povos chamamos de índios, a partir da Bíblia, compartilhada por católicos (portugueses e espanhóis) e protestantes (como os ingleses). Para os europeus da época, a explicação só podia estar no texto bíblico, tomado de forma literal e não metafórica, de uma maneira que, depois, seria chamada de fundamentalista (Vasconcellos 2008; Funari 2009).

Esses novos habitantes eram diferentes dos que os europeus estavam acostumados, como constatamos na narrativa da Carta Pero Vaz de Caminha ao Rei Dom Manuel sobre o achamento do Brasil sob o comando da expedição de Pedro Álvares Cabral em 1500 (Carta de Pedro Vaz de Caminha, 2002).

E sempre enfatizavam a inocência desses novos habitantes. Podemos observar o caso espanhol, em especial o contato de Cristóvão Colombo ao se deparar com esses habitantes e pensando na possibilidade de ter alcançado seu objetivo de chegar às Índias Orientais através do oceano Atlântico e suas ações frente a essa nova descoberta (Todorov, 1999).

Essa perspectiva dos europeus em procurar elementos cristãos dos habitantes do Novo Mundo foi o âmago do desconhecimento dos europeus, que gerou um genocídio em um primeiro momento, como, a conquista do Império Asteca por Cortes e do Império Inca por Francisco Pizarro, em segundo momento.

Para Laming-Emperaire (1980, p.29-31),

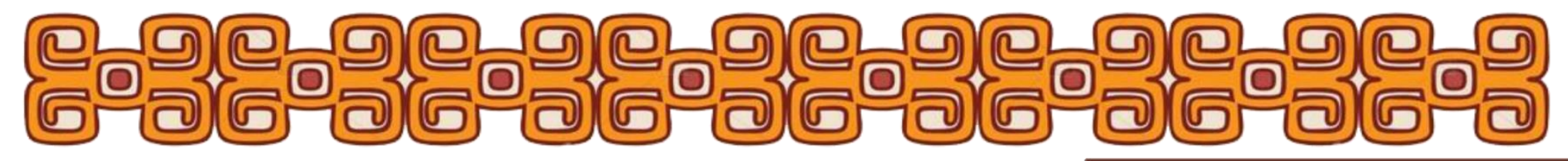




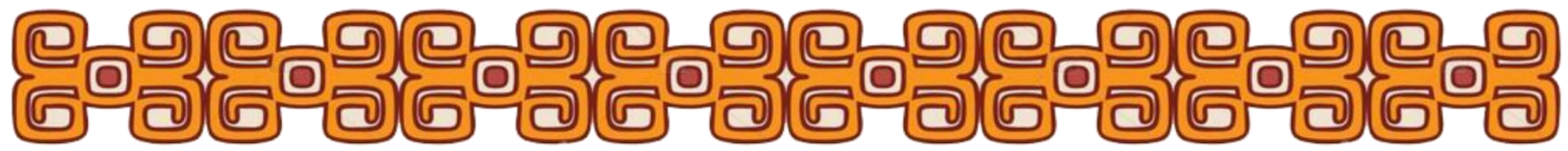

A segunda lenda, segundo Laming-Emperarie (1980), seria a do continente perdido de Mu ou Lémurie, estaria localizado entre o continente asiático e americano, inserido no oceano Pacífico e sendo submerso pelo mesmo, obrigando seus habitantes a migrarem para o continente americano. Tendo como principal pesquisador o zoólogo alemão Ernest Heinrich Philipp August Haeckel (1834-1917) suas ideias foram retomadas pelo inglês James Churchward (1851-1936), na década de 30 do século XX.

Dentre todas as civilizações da antiguidade a que possui mais menções sobre essa questão é a cultura fenícia, nela encontramos apontamentos que variam desde fontes bíblicas até prováveis presenças físicas. Os Fenícios se caracterizaram pela sua habilidade de navegação nos mares e Harden (1971) afirma que existiria a possibilidade de os fenícios terem alcançados as ilhas Canárias, Açores e Madeira. Percebemos a navegação próxima à costa dos continentes, segundo o mesmo Harden, chegando até o mar Vermelho, demonstrando assim sua perícia na arte da navegação. A possibilidade e viagem ocasional dos fenícios até a América sempre pareceu algo possível.

Dentro desse quadro, apesar da falta de dados sobre os fenícios terem alcançado o continente americano, há fontes bibliográficas que afirmam a possibilidade de vestígios fenícios no Piauí. Reinaldo Coutinho (2000) sintetiza que essa possibilidade da presença fenícia seria a mística que gira em torno de "Sete Cidades" localizada no município de Brasileira, no Piauí, onde segundo Coutinho (2000) seria utilizada para organizar reuniões entres os fenícios e tupis. Tudo demasiado especulativo.

É muito complexo fazermos inferências da presença desses povos da antiguidade no continente americano e sem uma fundamentação sólida se pode cair em descrédito acadêmico. Martin (1996) trata como impossível a presença fenícia no Piauí e adjetiva Ludwig Schwennhagen de "semi-louco", mas não deixando de ressaltar a importância de conhecermos esses mitos e lendas, para sabermos um pouco mais da História da América. Aprende-se muito sobre as narrativas dos europeus, desde o século XV, com interpretações bíblicas, clássicas greco-romanas ou

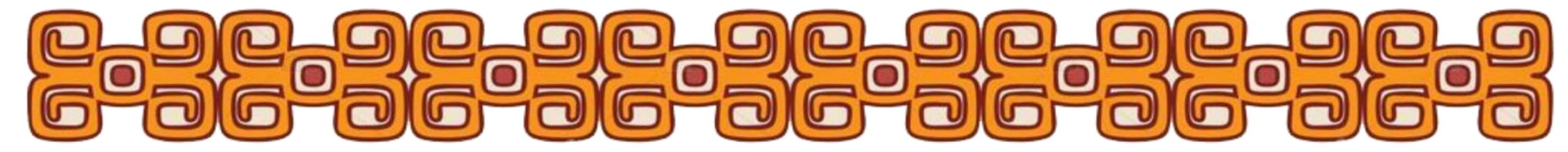




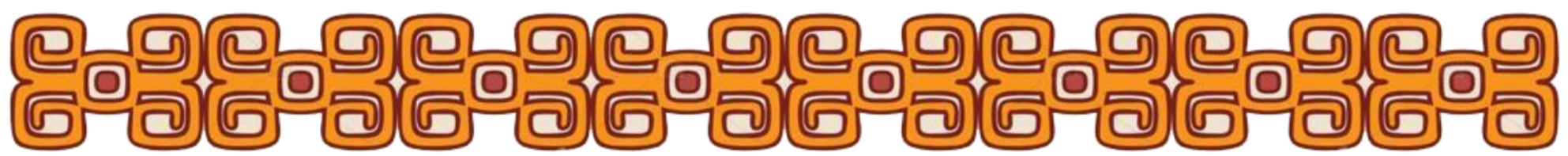

Portanto, a teoria de Ales Hrdlicka ganhou grande reputação no meio acadêmico e se tornou paradigma importante para o desenvolvimento das pesquisas arqueológicas no continente americano. Laming-Emperaire (1976) afirma que a aceitação das idéias de Hrdlicka pela comunidade cientifica, tornou-se um dos caminhos para o estudo do povoamento da América.

Para Ruiz (1953), Ales Hrdlicka acreditava nessa unidade mongoloide dos seres humanos americanos. Propondo quatros "momentos migratórios", o primeiro momento migratório, mais antigo, com indivíduos que possuiriam crânios dolicocéfalos que teriam originado as tribos iroqueses, astecas e algumas outras; o segundo momento migratório, por indivíduos de crânio braquicéfalo que teriam chegado até o continente sul americano; terceiro momento e quarto momento, por migrantes que dariam origem aos esquimós que estabeleceriam no extremo norte do continente americano.

Dentro dessa perspectiva, procuraram-se outros elementos que pudessem fornecer uma confirmação da presença dos seres humanos no continente americano, devido a não existir uma técnica de datação absoluta (carbono 14) até final da década de 1940, dificultando a construção de quadros cronológicos seguros. MacNeish (1996, p.187) ressalta a interpretação de artefatos líticos ainda antes das datações: "Na década de 1930, Clovis foi utilizado como um marco da presença humana nas Américas [...]" e as pontas de Folsom na década de 20, no Novo México (EUA). Laming-Emperaire (1973 a) considera a indústria de pedras lascadas com características grosseiras (choppers), logo, como sendo referências para caracterizar esses povos "caçadores-coletores". Com a utilização da técnica de datação do carbono 14, começou-se a construir quadros cronológicos mais precisos para o continente americano e assim correlacionando os dados entre si.

Martin (1996) afirma que essa corrente que situa o povoamento das Américas entre 10 a 12 mil anos atrás é defendida por grupos da Arqueologia norte-americana, em especial o Bureau American Ethnology, da Smithosian Institution of América (onde Hrdlicka foi diretor), seguindo muito dessa das idéias de Hrdlicka, sendo principais pesquisadores, Thomas Lynch, Dena Dinacauze e Betty Meggers (em um momento de sua carreira acadêmica e é interessante por ter influenciado a Arqueologia brasileira).

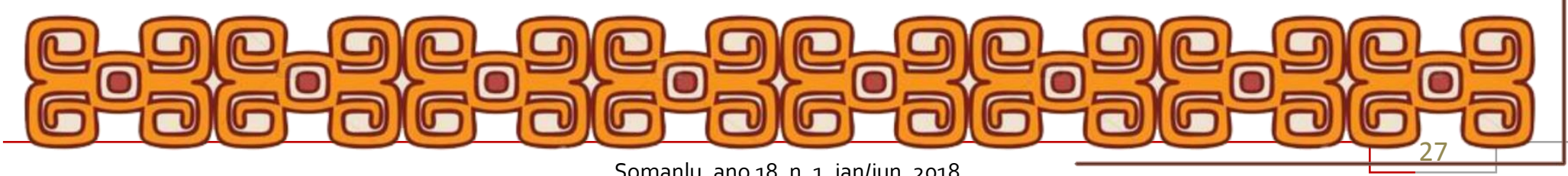




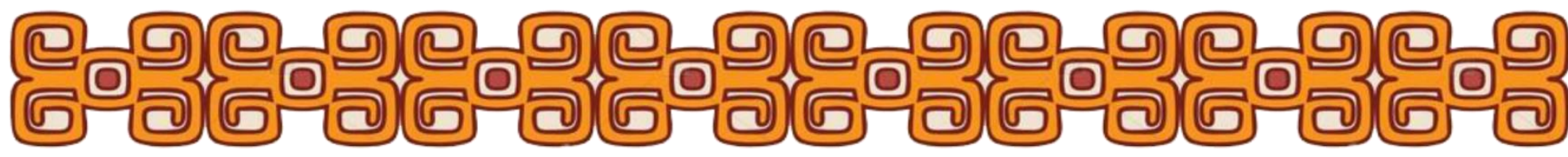

crítica ao método tipológico e a Escola Histórico-Culturalista, logo, a Arqueologia buscaria um status de ciência mais próxima a ciências da natureza, ou como, afirmou David L. Clarke (1937-1976) com a "Nova Arqueologia" no seu artigo intitulado, "Arqueologia: a perda da inocência" de 1973.

Nessa perspectiva, devemos ressaltar a importância das datações das glaciações nesse contexto, sendo responsáveis pelo aparecimento de uma ponte "biogeográfica" entre a Sibéria, na Ásia e o Alasca, na América do Norte, durante a última glaciação de Wisconsin por volta 75 a 10 mil anos atrás, permitindo assim, um abaixamento no nível do oceano pacífico e criando as condições terrestres para a migração tanto humana quanto de animais.

Dentro da Arqueologia brasileira essa visão da primeira migração humana via Beríngia e depois, espalhando-se pela as demais partes do continente, vem sendo defendida pelo bioantropólogo Walter Neves, da USP, mas com algumas modificações nos momentos migratórios. Estudou um crânio achado pela Missão Francesa (19741975) em Lagoa Santa, de características africanas e sendo considerado o crânio mais antigo do continente sul americano, batizada de Luzia e com aproximadamente $11 \mathrm{a}$ 11,5 mil anos atrás e assim propondo o "modelo dos dois componentes biológicos principais" (Neves 2006) afirmando que a migração inicial teria ocorrido por volta de 18 mil anos atrás.

\subsubsection{UMA VISÃO SOBRE O POVOAMENTO PELO SUL DO CONTINENTE AMERICANO}

Essa corrente do povoamento do continente é defendida pela "escola francesa" de Arqueologia, que dividimos em três momentos distintos, selecionando os principais representantes e sua influência para a Arqueologia brasileira. Em um primeiro momento, consideramos como precursor o etnólogo Paul Rivet (1876-1958), com seu artigo "Les Malayos-Polineses en Amérique" em 1926, fazendo inferências da possibilidade da travessia marítima de povos localizados na Oceania para o continente americano. Em seus estudos, Rivet procurou analogias entre esses dois extremos

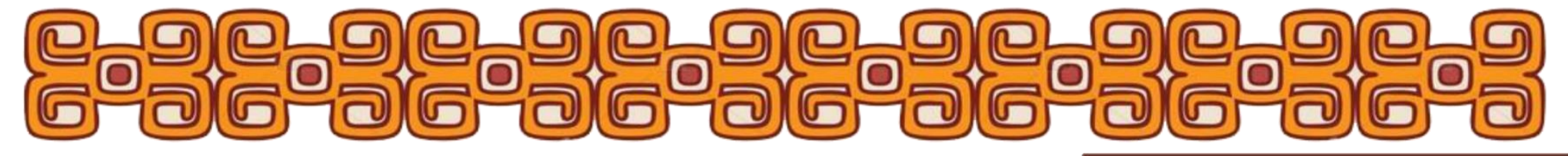




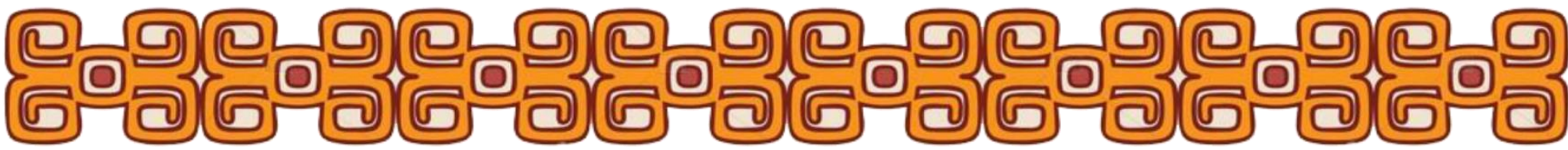

geográficos, no intuito de validar suas hipóteses e, talvez, a obra que sintetize melhor essas ideias seria "As origens do homem americano" na década de 40 do século XX.

Como não é possível retroceder no tempo, caberia apenas tentar conjecturar e tentar formular hipóteses. Tanto Rivet (1960) quanto Laming-Emperaire (1980) relatam a experiência de Thor Heyerdahl (1914-2002) através de suas pesquisas buscando demonstrar os contatos entre os polinésios e a América, por fim realizando essa travessia do oceano pacifico numa jangada em 1947, demonstrando na prática essa possível via do povoamento da América.

Rivet (1960) afirma que os elementos culturais que permitiriam fazer analogia entre os melanésios os povos indígenas americano são muitos, como: armas (sarabatana, propulsor, tacape anular e estrelado, arco); utensílios (enxó de cabo em cotovelo); navegação (remo em forma de muleta, embarcação, feita com canas, jangada, piroga dupla); objetos de uso doméstico (pilão de madeira, assentos e travesseiros de madeira, rede); vestuários e adornos (capa de fibras vegetais contra a chuva); cozinha (preparação de bebidas alcoólicas por mastigação de tubérculos ou de grãos); a introdução do tifo murino por ratos que teriam vindo nas embarcações e elementos linguísticos.

Acerca dos contatos entre os polinésios e o continente americano, Rivet (1960) através de estudos linguísticos demonstrou por analogias de semelhanças entre algumas palavras polinésias e alguns povos americanos (batata-doce, polinésia se chama kumara, enquanto no Haiti, umara), introdução do inhame (dioscorea alata), coco da Bahia (cocos nucifera) e da batata-doce (hibicus tilaceus).

Em um primeiro momento, a ideia de Paul Rivet acerca do povoamento da América, recebeu muita crítica da comunidade acadêmica e assim gerando muitos questionamentos sobre a sua fundamentação, como, a localização dos primeiros sítios desses navegantes e as possíveis vias de acesso. Devemos ressaltar que a importância das glaciações de Wisconsin nesse contexto, provocando a diminuição dos níveis dos oceanos, reduzindo distâncias e criando pontos de apoio, como ilhas.

Em um segundo momento, afirma Prous (1999), os alunos de Rivet, Annette e Josef Emperarie vieram ao Brasil em 1954-56, no intuito de pesquisar acerca das teorias de Paul Rivet, buscando uma possível validação, criando o primeiro curso de

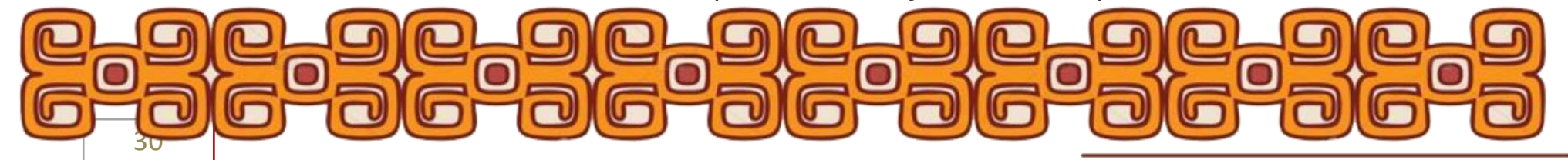




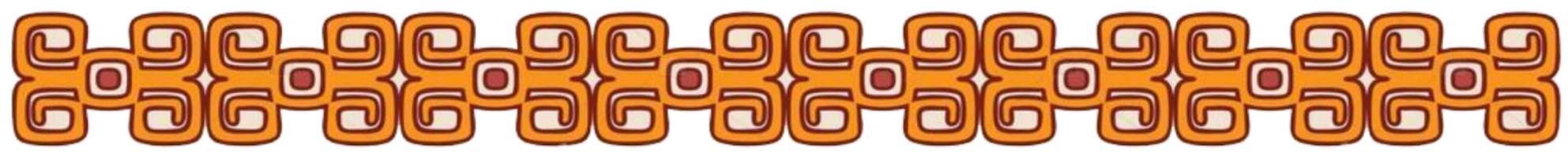

lítico na Universidade Federal do Paraná década de 50 e depois uma missão arqueológica sob o comando de Laming-Emperaie em Lagoa Santa, Minas Gerais e estendendo-se para o Piauí na década de 70, sob o comando de Guidon. Foram responsáveis pelo treinamento de uma outra geração de arqueólogos brasileiros, diferente da anterior treinada por Evans e Meggers.

Nesse segundo momento, Laming-Emperaire ao longo de suas pesquisas chegou uma não validação das ideias do povoamento da América de Paul Rivet (1960).

Para Laming-Emperaire (1980, p.46),

Seus argumentos são para uns acima de tudo etnológicos, para os outros autores sobretudo arqueológico. A medida que o tempo passou não se satisfaz mais de assinalar analogias, mas em pesquisar as vias e as modalidades dos contatos múltiplas.[...] Suas teorias que foram acolhidas por muitos e sobretudo pelos norte-americanos com um grande ceticismo, estão atualmente largamente ultrapassadas. A etnologia, a lingüística e a Arqueologia depois de 50 anos de progresso, que não é mais possível colocar os problemas da mesma forma que foram colocados por Rivet. Suas hipóteses não foram inúteis porque elas obrigaram esses mesmos que os criticaram a formular os problemas em termos mais precisos e mais claros.

Laming-Emperaire (1976) afirma que o período inicial do povoamento da América pode ter ocorrido por volta 60 mil anos atrás, mas não excluindo a possibilidade de um povoamento de 80 a 100 mil anos atrás, sendo a passagem do estreito de Bering a via principal de acesso e mais antiga desses primeiros migrantes, assim Laming-Emperaire (1980) propondo três vagas populacionais: a primeira vaga migrou por volta de 70 mil a.c; a segunda vaga, por volta de 28,5 a 25 mil anos atrás; terceira vaga, por volta de 13 a 11 mil anos atrás e; a partir de 10 mil atrás, a região não apresentava mais obstáculos para a migração de outros povos, recebendo outros fluxos populacionais (Funari e Noelli 2002).

Fica claro a partir do terceiro momento, com o desenvolvimento dos trabalhos da Missão Francesa em dois focos; o primeiro, em Lagoa Santa, com o Prous e; o segundo, com Guidon no Piauí, ambos na década de 70. Ao longo de suas pesquisas, ambos pesquisadores realizaram importantes trabalhos na Arqueologia brasileira e chegaram a conclusões diferentes acerca do povoamento do continente americano.

Para Prous (1992, p.119-120),

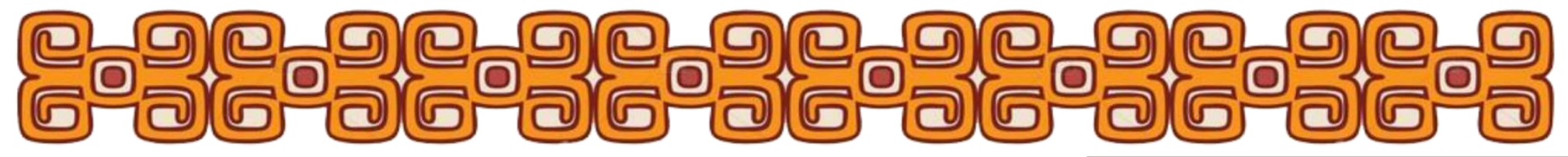




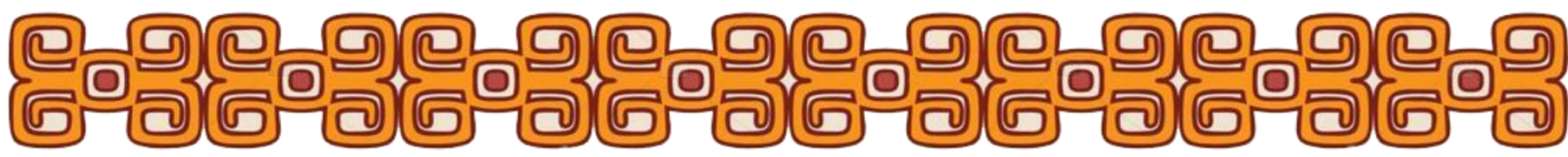

A presença do Homem no Nordeste é, de maneira muito bem documentada, comprovadamente muito antiga. A seqüência de cerca de 46 datações obtidas para diferentes sitos no Piauí, a longa coluna estratigráfica no abrigo Toca do Boqueirão do Sítio da Pedra Furada que cobre cerca de 60.000 anos, a abundância da indústria lítica, em quartzo e quartzito ligada a essas datas antigas, a presença de fogueiras estruturadas bem definidas nas camadas datadas, a existência de blocos de parede caída, com pinturas nessas mesmas camadas, são dados irrefutáveis.

Nessa estratigrafia não há inversão de camadas, foi possível definir-se o contexto arqueológico.[...] Na toca do Boqueirão do Sítio da Pedra Furada a descoberta das camadas mais antigas do que 32.000 anos foi feita em agosto de 1987 com o prosseguimento das escavações, iniciadas em 1978 e que se prosseguiram em 1980, 1981, 1984, 1985 e 1986.

O marco inicial da pesquisadora Guidon no sentido de tentar quebrar esse paradigma de Clóvis e chamar a atenção para um possível povoamento pleistoceno no Brasil, é percebido quando Guidon e Delibrias (1986, p.321) afirmam:

\begin{abstract}
O panorama que o homem não chegou ao continente americano antes da última glaciação tem se baseado pelo fato que até agora o conhecimento e os sítios arqueologicamente datados não possuírem de antiguidade muito recuada. Mas agora informe de datações radiocarbonicas oriundo do sítio brasileiro qual fixou que o homem estaria vivendo na América do Sul por no mínimo 32,000 anos atrás. Estes novos achados surgem vindo das vastas pinturas rupestres do Boqueirão do Sitio da Pedra Furada, as paredes e o teto do qual são decoradas com um rico quadro da pré-história. Nós escavamos uma seqüência que possuía uma abundante indústria lítica e estruturas em todos os níveis. Datações de carbono 14 oriundas do carvão vegetal estabelecem uma cronologia continua indicando presença humana

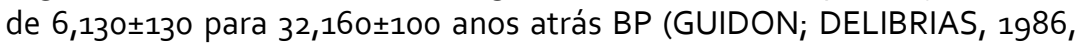
p.321).
\end{abstract}

Neste sentindo, Guidon e Delibrias com esse artigo tentam chamar atenção da comunidade cientifica para um povoamento do continente sul americano mais recuado. Ali, fizeram inferências acerca do paradigma de Clóvis e suas deficiências em explicar as primeiras migrações para o Novo Mundo, sendo considerada as duas faces de uma realidade do povoamento da América.

Segundo Guidon (1984, p.153),

Atualmente se defrontam duas "escolas": a dos "prudentes" e a dos "ousados". A primeira defende a teoria de que a América só foi povoada muito tardiamente, há cerca de 15.000 anos e a segunda propõe idades existentes recuadas, entre 30.000 a 70.000 anos, para presença humana no Novo Continente.

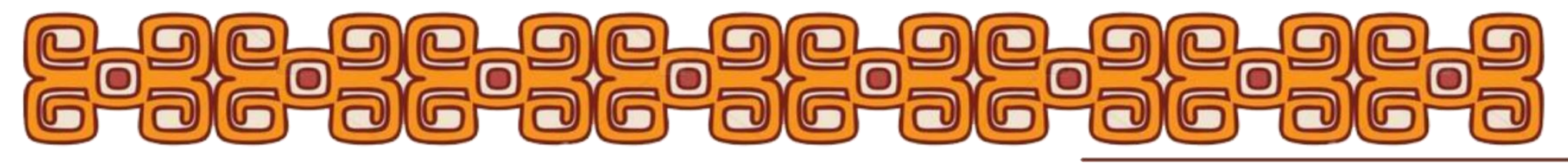




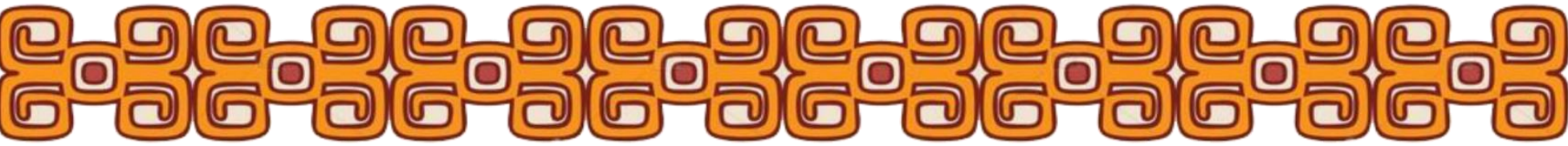

Como explicar as datações tão recuadas no continente sul americano, em especial, na região Nordeste do Brasil? E de onde vieram esses migrantes e por onde adentraram no continente? O desconcertante sítio da Pedra Furada provocou um processo inicial de revisão nas teorias e nas explicações acerca do povoamento da América, evidenciadas no I Simpósio do Povoamento da Américas em 1993, em São Raimundo, no Piauí. Umas das primeiras vozes a afirmar que o "paradigma Clóvis" estaria ultrapassado foi o pesquisador canadense MacNeish.

De acordo MacNeish (1991, p.199),

Mais de 80 componentes pré-clovis, que vão de Nenanna no Alasca até
Monte Verde no sul do Chile, produziram evidências da ocupação
humana.[...] A velha teoria excessivamente abrangente de uma única e
rápida migração do povo Clovis iniciando-se há 12.000 BP não é mais
defensável e tem de ser substituída com modelos que se adaptem aos novos
fatos. Abrimos a caixa de Pandora, e apenas a pesquisa futura determinará
quais modelos emergirão.

Outro sítio arqueológico fora do Brasil considerado pré-clóvis é o sítio de Monte Verde no Chile, escavado por Tomas Dillehay. Dillehay (1996) afirma que abrangeria desde 12.800 a 33.000 BP, sem continuidade. Dentro do território brasileiro possuímos sítios como datações superiores a 13.000 mil anos AP, como, Toca da Esperança, escavado por Maria Conceição Beltrão. Segundo Beltrão (1993), esse sítio possuiria com datações que se estenderiam de até 295.000 anos atrás, configurando a possibilidade de uma ocupação do Homo erectus, sendo alvos de muitas críticas por parte da comunidade acadêmica.

Nessa perspectiva, necessitamos de outras ferramentas para aprofundar-nos na questão do povoamento das Américas, a parasitologia seria uma delas. Através dos estudos parasitas poderíamos conhecer a distribuição dos seres humanos no continente e fazermos inferências acerca das vias de povoamento.

Segundo Araújo e Ferreira (1996, p.106),

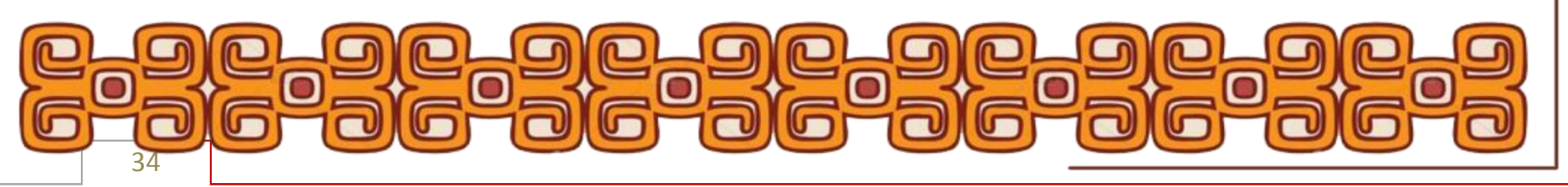




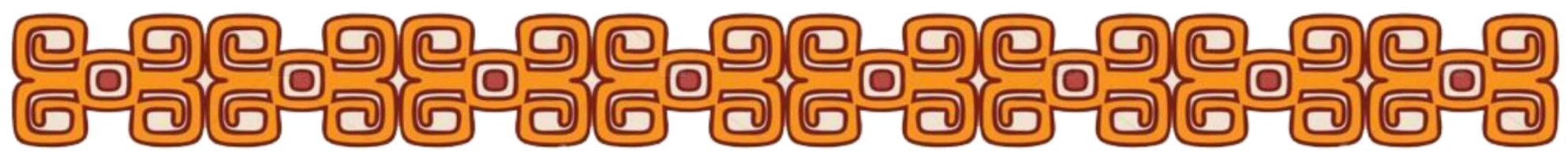

As espécies biológicas não surgem em mais de um ponto geográfico, como pressupõe a teoria de evolução das espécies de Charles Darwin. As infecções parasitárias são, portanto, marcadores biológicos de difusão de hospedeiros, acompanhadas sua ocupação de novos territórios, à medida que as condições mesológicas o permitem[...].A contribuição da paleoparasitologia foi conclusiva para esta questão. O encontro de parasitos em material arqueológico datado de períodos pré-colombianos estabelece, no espaço e no tempo, quais infecções parasitárias encontravam-se entre os ameríndios em épocas à colonização europeia e ao tráfico negreiro.

Rivet (1960) afirma que o médico americano Fred L. Sopper realizou estudos em tribos indígenas no Paraguai em 1927 e demonstrou a possibilidade de que certos parasitas poderiam ter sido introduzidos por outras vias, como, Ancilóstomo Duodenale. Esse é um caso interessante de abordamos, em especial, o ciclo de vida da parasita em questão encontrada na Toca do Boqueirão da Pedra Furada, onde coprólitos, com datações de $7.230+-80$ anos AP.

Para Araújo e Ferreira (1996, p.106-110),

As diferenças encontradas nos padrões de infecção levaram a interpretação de que algumas populações indígenas seriam de origem asiática, mas sua penetração deveu-se a migrações transpacíficas, em períodos pré-colombiano (Manter, 1967; Fonseca, 1972). Essas conclusões baseavam-se em teorias de povoamento da América pela via transpacífica (Rivet, 1926) e na, impossibilidade das parasitoses encontradas, manterem seu ciclo de transmissão sob as baixas temperaturas da região da Sibéria e Alasca (Nicole, 1932). Segundo Stewart (1960), o clima da região de Bering teria agido como filtro para as infecções existentes nas populações que seguiram essa rota.[...] A infecção humana por ancilostomídeos transmitese de hospedeiro a hospedeiro, com estágios larvares obrigatoriamente evoluindo no solo, sob condições específicas de temperatura e umidade que, em condições idéias, dá-se entre $25^{\circ}$ e $30^{\circ} \mathrm{C}$. Nesse caso, as migrações humanas pré-históricas pela via de Bering não poderiam ter introduzido esta parasitose na América, em virtude das baixas temperaturas no solo, o longo caminho percorrido sob essas condições climáticas, e as gerações de hospedeiros que se sucederam das Sibéria até América do Norte.[...] É preciso notar que a presença de infecção por Ancylostoma duodenale e Trichuris trichiura da América pré-colombiana é um indicador de contatos transmarítimos, mas não necessariamente de intensos, ou numerosos, movimentos migratórios. Poucos contatos seriam capazes de infectar uma população já existentes (Marasciulo, 1992). Por outro lado os dados indicam que a possibilidade de navegação já existiam há mais de 7.200 anos (Araújo et al., 1988).

Na parte norte do continente americano, a infecção de parasitose mais comum

foi por Enterobius vermiculares com datações de até 10.000 anos atrás, Araújo,

Gonçalves e Ferreira (2006) afirmam que essa parasitose teria vindo com os seres

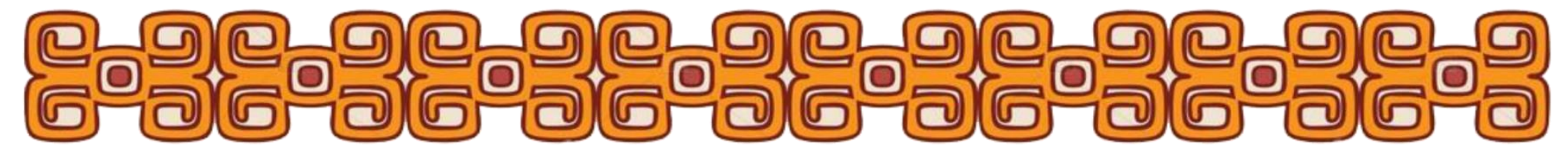




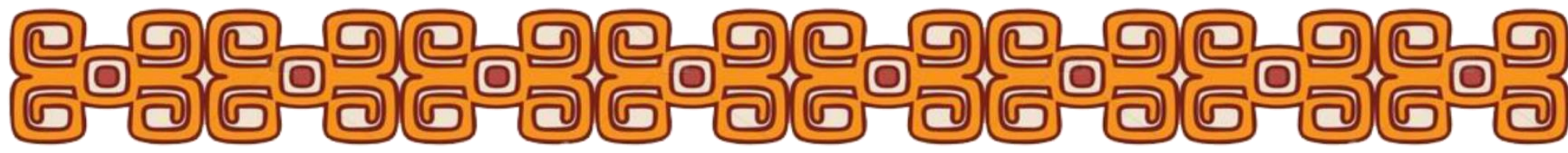

\title{
CONSIDERAÇÕES FINAIS
}

Podemos concluir que o povoamento do continente americano constitui um assunto muito complexo e continuará gerando muitas controvérsias. Estando a Arqueologia brasileira aberta para mais pesquisas de pré-história, não pode ser um discurso dogmático imposto. Temos como certo que mais estudos serão necessários para a construção de novas possiblidades. Essa construção será possível graças aos trabalhos cientifico dos arqueólogos no dia-a-dia em suas escavações nos sítios, resultando na abertura de novas pesquisas e reflexões. Talvez, somente o tempo, as pesquisas arqueológicas e as inovações tecnológicas possam melhor elucidar essa questão fundamental e insistente.

Para Laming-Emperaire (1980, p.13),

\begin{abstract}
As hipótesis são múltiplas. Sua simples enumeração é impresionante. Esses são principalmente os Fenicios, os Assírios, os Egipcios, os Cananeus, os Israelitas, os Troianos, os Gregos, os Etruscos, os Romanos, os Celtas que são utilizados para explicar as civilizações amerindios, ao menos as civilizações avançadas em relação as outras, aquelas "selvagens", pouco se pesquisa as origens. Depois, a medida que o tempo passou, se invocou também os tártaros, os Hunos, os Indus, os Chineses, os Budistas, os Africanos [...], os Vikings, os Gauleses, os Irlandeses, os Bascos, os Potugueses, os Espanhóis, os Franceses. Em uma palavra todas as épocas antigas dentro das quais mistura-se a destruição de uma vila ou de uma cultura (Tróia), naufrágio de uma armada (Alexandre) ou das conquistas ou das invasões nas terras distantes (os Hunos, os Vikings) são sucetivéis de serem utilizadas.
\end{abstract}

Onde houver um navio naufragado, uma civilização que parece desconhecida ou mesmo prováveis presenças físicas de povos desaparecidos, construiu-se uma mística sobre as origens dos habitantes do continente americano. Isso representaria uma busca dos colonizadores em explicar ou mesmo como justificar a sua dominação sobre as tribos indígenas americanas. Parece-nos necessário afastar-se de toda visão imperialista ou colonialista e estar sempre abertos às novas descobertas.

\section{AGRADECIMENTOS}

Agradecemos a Maria Conceição Beltão, Madu Gaspar, Niède Guidon, Walter Neves e André Prous. Mencionamos o apoio institucional da UFAM, Unicamp, CNPq e Fapesp. A responsabilidade pelas ideias restringe-se aos autores.

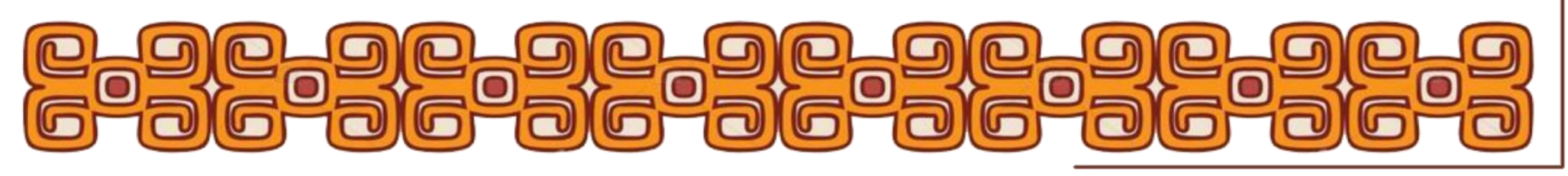




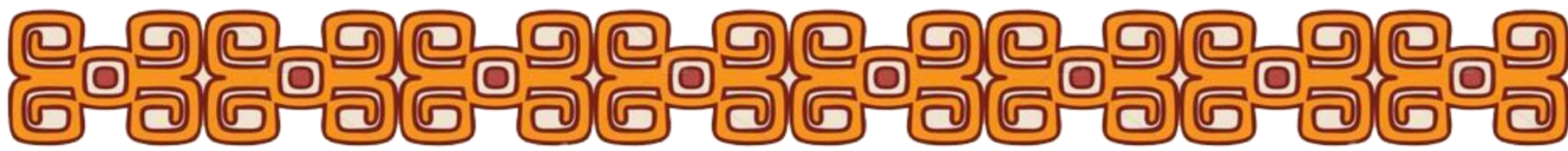

\section{REFERÊNCIAS}

ARAÚJO, Adauto; FERREIRA, Luiz Fernando. Paleoparasitologia e povoamento da América. In: Fumdhamentos - Revista da Fundação do Museu do Homem Americano. São Raimundo. Vol 1, n 1, 1996, p.105-114.

ARAÚJO, Adauto G.; GONÇALVES, Marcelo; FERREIRA, Luiz F. Migrações Préhistóricas e paloeparasitologia. SILVA; Hilton P.; RODRIGUES-CARVALHO, Claudia. In: Nossa origem: o povoamento das Américas, visões interdisciplinares. Rio de Janeiro: Vieira \& Lent, 2006.

BAHN, P.; REFREW, C. Arqueologia: Teorias, métodos y practica. Madrid: Akal, 1993.

BELTRÃO, Maria da Conceição. A região arqueológica de Central, Bahia, Brasil: A Toca da Esperança, um sítio arqueológico do pleistoceno médio. In: Fundhamentos. Revista da Fundação do Museu do Homem Americano. São Raimundo. Vol 1, no ${ }_{1}$ 1996, p. 115-146.

Carta Pero Vaz de Caminha ao Rei Dom Manuel sobre o achamento do Brasil. São Paulo: Editora Martin Claret, 2002.

COUTINHO, Reinaldo. Desvendando Sete Cidades. Teresina: Edições Tur-Troya. 2000.

DILEHAY, Tom D. Uma sinopse do registro arqueológico de Monte Verde. Fumdhamentos. In: Revista da Fundação do Museu do Homem Americano. São Raimundo. Vol 1, n 1, 1996, p.147-151.

FUNARI, P.P.A. \& NOELLI, F.S. Pré-História do Brasil. São Paulo, Contexto, 2002.

FUNARI, P.P.A. Resenha de Fundamentalismos, de Pedro Vasconcellos, Revista Estudos de Religião, 3, 2009, 124-126.

GASPAR, MaDu. Sambaqui: Arqueologia do litoral brasileiro. Rio de Janeiro: Jorge Zahar Editor, 2004.

GUIDON, Niède. Reflexões sobre o povoamento da América. In: Dedalo, n 23, 1984, p.153-156.

GUIDON, Niède; DELIBRIAS, Georgette. Carbon - 14 dates point to man in the Americas 32,000

years ago. Nature, London, vol. 321, n० 6072, 1986, p.385-408.

GUIDON, Niède. O Pleistoceno no Sudeste do Piauí. In: Anais I Simpósio de PréHistória. 30, 30-3 ABR. Pernambuco, 1991. p.17-19.

GUIDON, Niède. A maior concentração de pinturas rupestres do mundo está no Piauí. In: Sapiência, Ano 2, No 5, 2005, p.6-7.

HARDEN, Donald. Os Fenícios. Lisboa: Editora Verbo, 1971. p.170-188.

LAMING-EMPARIE, Annette. Problèmes de Préhistorie Bresilienne. In: Annales: Economies, Societes et Civilisations, Paris,1973 b. p. 229-254.

LAMING-EMPARIE, Annette. L'Archaeologie Prehistorique. Paris: Editions du Seul, $1973 a$.

LAMING-EMPARIE, Annette. Le plus ancien peuplement de I'Amérique. In: Bulletin de la Societé prehistorique française, $n^{\circ}$ 73. (CRSM 9), 1976. p.280-287.

LAMING-EMPARIE, Annette. Le problème des orgines americaines: theories, hypothèses, documents. Paris: Editions de la maison des sciences de l'homme, 1980. LAVALLÉ, Daniele. Promesse d'Amerique: La prehistoire de I'Amérique du Sud.

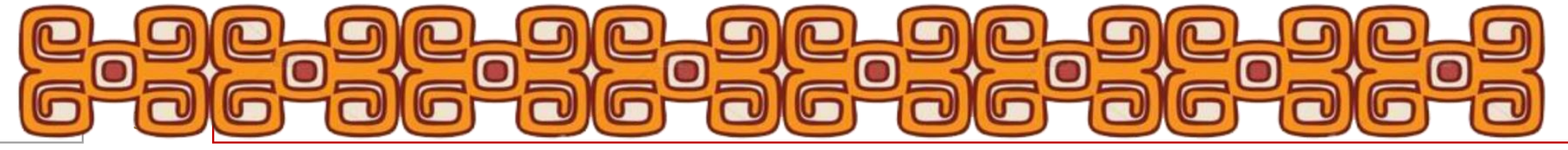




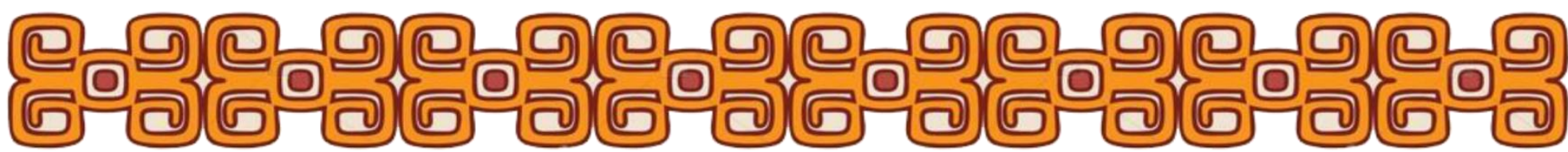

Pairs: Hachette, . 1995. p.9-137.

MACNEISH, Richard. Provas Pré-clovis de pendejo e suas implicações. In: Fumdhamentos - Revista da Fundação Museu do Homem Americano. São Raimundo Nonato (PI). 1996, p. 171-200.

MARTIN, Gabriela. A Pré-história do Nordeste. Editora UFPE: Pernambuco, 1996.

NEVES, Walter. Origens do homem nas Américas: fósseis versus moléculas. In: SILVA; Hilton P.; RODRIGUES-CARVALHO, Claudia. Nossa origem: o povoamento das Américas, visões interdisciplinares. Rio de Janeiro: Vieira \& Lent, 2006.

PROUS, André. Arqueologia Brasileira. Brasília: Editora Unb, 1992.

PROUS, André. Arqueologia, Pré-história e História. In: TENÓRIO, Maria Cristina (org). Pré-história da terra Brasilis. Rio de Janeiro: Editora UFRJ, 1999.

PROUS, André. O Brasil antes dos brasileiros: a pré-história do nosso país. Rio de Janeiro: Jorge Zahar Editor, 2006. p. 7-32.

RIVET, Paul. As Origens do Homem Americano. São Paulo: Editora Ahembi, 1960.

RUIZ, Felipe Gonzalez. Evolucion de la Cultura en America. Madrid: Ediciones Sapientia, 1953.

TODOROV, Tzvetan. A Conquista da América: A questão do outro. $2^{a}$ Edição São Paulo: Martins Fontes, 1999.

TRIGGER, B. História do pensamento arqueológico. São Paulo: Odysseus editora, 2004 .

Vasconcellos, P. Fundamentalismos. São Paulo, Paulinas, 2008.

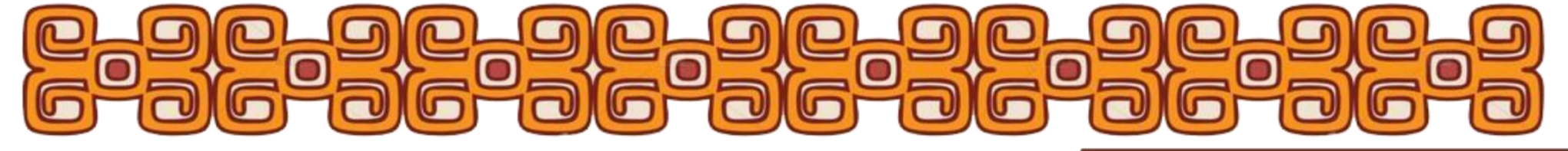

